\title{
Registration of 'Kharoba': A Bread Wheat Cultivar Developed through Doubled Haploid Breeding
}

\author{
J. Elhaddoury, S. Lhaloui, S.M. Udupa, * B. Moatassim, R. Taiq, M. Rabeh, \\ M. Kamlaoui, and M. Hammadi
}

\begin{abstract}
'Kharoba' (Reg. No. CV-1068, PI 664028), a hard red spring wheat (Triticum aestivum L.) cultivar developed using doubled haploid technology by the Institut National de la Recherche Agronomique (INRA), Morocco, and tested as 00DHBW300, was approved for release in 2010 by the Office National de Sécurité Sanitaire des Produits Alimentaires (ONSSA; reg. no. 450-11), Morocco. Kharoba was selected from the doubled haploids derived from the cross 'Altar 84'/Aegilops squarrosa 221//'Pastor'/3/k134(6)/'Veery'//'Bobwhite'/'Pavon'/4/'Tilila'. Kharoba is a widely adapted, high-yielding, short, erect cultivar having good end-use qualities. Kharoba is resistant to leaf rust (caused by Puccinia triticina Eriks.), yellow rust (caused by P. striiformis Westend f. sp. tritici), the Hessian fly [Mayetiola destructor (Say)], and Fusarium head blight (caused by Fusarium graminearum Schwabe [teleomorph Gibberella zeae (Schwein.) Petch]). Kharoba has been released for cultivation under both rainfed and irrigated conditions. Kharoba is the first bread wheat cultivar developed through doubled haploid breeding in Morocco.
\end{abstract}

$\mathbf{W}$ heat (Triticum aestivum L.) is the number-one cereal crop with respect to area and production in Morocco. More than $85 \%$ of the wheat area in Morocco is under rainfed conditions. Various biotic and abiotic stresses limit the productivity of wheat under rainfed conditions, and consequently Morocco is not self-sufficient in wheat production most years. The Hessian fly [Mayetiola destructor (Say)] and leaf rust (caused by Puccinia triticina Eriks.) and yellow rust (caused by $P$. striiformis Westend $\mathrm{f}$. sp. tritici) diseases are the most destructive biotic stresses in the major cerealgrowing regions of Morocco, and high incidence levels regularly occur in the country, resulting in an estimated loss of $30-40 \%$ of the national production. Developing wheat varieties with better resistance is the most effective means of managing these stresses and improving productivity.

J. Elhaddoury, S. Lhaloui, B. Moatassim, R. Taiq, M. Rabeh, M. Kamlaoui, and M. Hammadi, Institut National de la Recherche Agronomique (INRA), B.P. 589, Settat, Morocco; S.M. Udupa, ICARDA-INRA Cooperative Research Project, International Center for Agricultural Research in the Dry Areas (ICARDA), B.P. 6299, Rabat, Morocco. Received 27 July 2011. *Corresponding authors (elhaddoury24@yahoo.fr); (S.Udupa@cgiar.org).

Abbreviations: FHB, Fusarium head blight; ONSSA, Office National de Sécurité Sanitaire des Produits Alimentaires.

Published in the Journal of Plant Registrations 6:1-5 (2012).

doi: 10.3198/jpr2011.07.0385crc

Posted online XX Feb. 2012.

(C) Crop Science Society of America

5585 Guilford Rd., Madison, WI 53711 USA

All rights reserved. No part of this periodical may be reproduced or transmitted in any form or by any means, electronic or mechanical, including photocopying, recording, or any information storage and retrieval system, without permission in writing from the publisher. Permission for printing and for reprinting the material contained herein has been obtained by the publisher.
Over the years, substantial progress has been accomplished by the Institut National de la Recherche Agronomique (INRA), Morocco in breeding for the Hessian fly-resistant wheat cultivars, and four bread-wheat varieties have been developed so far and released for cultivation in Morocco.

The changes in environmental conditions, pests, disease problems, and personal preferences over the years challenge the adoption of wheat cultivars by the farmers in the country. There is a need for cultivars that can better withstand diseases and pests and are suitable for cultivation under rainfed conditions. Therefore, genotypes improved specifically for resistance to the Hessian fly, yellow rust, and leaf rust and to new emerging diseases in Morocco such as Fusarium head blight (FHB; caused by Fusarium graminearum Schwabe [telomorph Gibberella zeae (Schwein.) Petch]) and improved end-use quality will better meet the productivity expectations and allow farmers to remain economically competitive while delivering high-quality wheat to consumers. Additional wheat cultivars can provide better options for farmers to choose according to their needs and thereby reduce the risk of crop losses. 'Kharoba' (Reg. No. CV-1068, PI 664028) is a new bread-wheat cultivar that has the potential to become popular among the farmers in Morocco given its competitive grain yield and quality, adaptation, and resistance to the Hessian fly, yellow rust, leaf rust, and FHB relative to other cultivars.

\section{Methods}

\section{Early-Generation Population Development}

Kharoba (00DHBW300) was selected from the doubled haploids derived from the cross 'Altar 84'/Aegilops squarrosa 221//'Pastor'/3/k134(6)/'Veery'//'Bobwhite'/'Pavon'/4/ 'Tilila'. The choice of lines for the crossing program was 
made by considering the high yield potential, drought tolerance, and resistance to biotic stresses such as leaf rust, yellow rust, and the Hessian fly. The synthetic hexaploid wheat (Altar 84/Aegilops squarrosa 221) used as a parent in the cross contributed several characteristics that are important for semiarid areas, such as enhanced adaptation and resistance to diseases and insect pests (Mujeeb-Kazi et al., 1996). The $\mathrm{F}_{1}$ seed (Altar 84/Aegilops squarrosa 221//Pastor/3/ k134(6)/Veery//Bobwhite/Pavon) was received in Morocco from CIMMYT-Mexico and screened for resistance to Hessian fly. The identified resistant lines were crossed with an adapted elite Moroccan variety, 'Tilila', to produce the hybrid of the cross (Altar 84/Aegilops squarrosa 221// Pastor/3/k134(6)/Veery//Bobwhite/Pavon/4/Tilila) in 2000. The anther culture technique was used to produce homozygous lines from this cross. Anthers of the hybrid were cultivated on C17 medium (Wang and Chen, 1986), and 732 plants were regenerated on R9 medium (Miller, 1963). Albinos and abnormal plants were eliminated, and haploid green plants were diploidized by treating them with colchicine solution $(0.2 \%)$. A total of 565 doubled haploids lines were developed. Spikes of the doubled haploids were covered with crossing bags to avoid out-crossing.

\section{Line Selection and Evaluation}

In 2001, 565 doubled haploids were tested for reaction to the Hessian fly in a greenhouse, maintained at $20 \pm 2^{\circ} \mathrm{C}$ and natural daylight settings. The doubled haploid lines were seeded in greenhouse wooden flats $(60 \mathrm{~cm}$ long by $40 \mathrm{~cm}$ wide by $10 \mathrm{~cm}$ deep) at a rate of one row of 25 seeds per line. Each flat contained one Hessian fly-resistant cultivar, 'Saada', and one susceptible cultivar, 'Nasma', as checks. When plants were at the two-leaf stage, the flats were covered with cheesecloth tents, and about 100 newly emerged and mated females were released in each flat. The flats were kept covered for about $5 \mathrm{~d}$ to allow eggs to hatch, and then the tents were removed. Twenty-one days later, plants were dug out of the flats and categorized as susceptible, stunted with dark green color, or resistant with normal growth and a light green color. This reaction was further confirmed under the microscope for the presence of live larvae on the susceptible plants and dead first instars on the resistant ones. A total of 68 lines were found to be resistant to the Hessian fly.

Yield and other agronomic traits were determined from replicated field trials with randomized complete block designs conducted either at a single location or multiple locations. The production practices, including conventional tillage and fertilization as recommended for Moroccan conditions (Karrou, 2003), were adapted for the field trials. The field resistances to leaf rust, yellow rust, FHB, and Hessian fly were recorded during the field trials under the natural inoculations/infestation in presence of susceptible symptoms on the susceptible cultivars and checks.

In 2002-2003, the 68 doubled haploid lines that showed resistance to Hessian fly were planted in two rows at Sidi El Aidi, an experimental station of INRA in Morocco (a low-rainfall rainfed wheat production zone with an annual average rainfall of $300 \mathrm{~mm}$; altitude $230 \mathrm{~m}$, lat. $33.17^{\circ} \mathrm{N}$, long. $7.40^{\circ} \mathrm{W}$ ). Selection was made for agronomic and morphological characteristics, such as maturity, fertility, tillering, height, and disease resistance. Forty selected lines were evaluated in the preliminary yield trials at Sidi El Aidi in 2003-2004 with two replications and four checks ('Arrihane', 'Achtar', 'Massira', and 'Mahdia') and planted in plots of $6 \mathrm{~m}^{2}$. The checks Arrihane (resistant to the Hessian fly, tolerant to leaf rust, and susceptible to yellow rust and FHB), Achtar (susceptible to the Hessian fly, leaf rust, yellow rust, and FHB), Massira (susceptible to the Hessian fly, leaf rust, yellow rust, and FHB), and Mahdia (tolerant to the Hessian fly and susceptible to leaf rust, yellow rust, and FHB) are widely grown bread-wheat cultivars in Morocco (Abbad-Andaloussi and Chahbar, 2005).

In the preliminary yield trial, 27 doubled haploid lines showed significantly higher grain yields than the average of the four checks and some of the individual checks. These higher-grain-yielding lines also showed resistance to the Hessian fly (tested under controlled conditions) and leaf rust (tested under field conditions in the presence of disease on susceptible cultivars and checks). Among the higher-yielding lines, line 00DHBW300 was the best, yielding $6102 \mathrm{~kg} \mathrm{ha}^{-1}$.

From the preliminary trial, a total of 20 doubled haploid lines were selected for the intermediate and advanced yield trials (2004-2005 and 2005-2006) in four environments namely, Sidi El Aidi, Jamaa Shaim (a low-rainfall rainfed wheat production zone with an annual average rainfall of $330 \mathrm{~mm}$, altitude $180 \mathrm{~m}$, lat $32.35^{\circ} \mathrm{N}$, long $8.85^{\circ} \mathrm{W}$ ), Tassaout (irrigated site with an average rainfall of $266 \mathrm{~mm}$, altitude $465 \mathrm{~m}$, lat $31.42^{\circ} \mathrm{N}$, long $6.47^{\circ} \mathrm{W}$,), and Khemis Zemamra (a low-rainfall rainfed wheat production zone with an annual rainfall of $300 \mathrm{~mm}$, altitude $160 \mathrm{~m}$, lat $32.62^{\circ} \mathrm{N}$, long $8.71^{\circ} \mathrm{W}$ ). Yield and other agronomic traits were determined from the replicated field trials conducted at the four locations using randomized complete block designs with four replications and plot that were $6 \mathrm{~m}$ long by $1.5 \mathrm{~m}$ wide with $20-\mathrm{cm}$ row spacing. Various diseases and pests resistance were recorded (Prescott et al., 1986) during the trials. At the end of the advanced yield trial (2005-2006), the three best-yielding lines-00DHBW103, 00DHBW146, and 00DHBW300-were selected based on their superior performance over all four checks, especially for grain yield in the low-rainfall environments of Sidi El Aidi and Jamaa Shaim. These three doubled haploid lines were submitted to the Office National de Sécurité Sanitaire des Produits Alimentaires (ONSSA), Rabat, Morocco, for testing in nationwide trials.

In the nationwide trials (2008-2009 and 2009-2010), these three lines were evaluated in replicated field trials using randomized complete block designs in the three wheat-growing zones of Morocco, namely the irrigated wheat production zone (at one site: Ouled Gnaou), the high-rainfall rainfed wheat production zone (at three sites: Bouznika, Marchouch, and Mrisa), and the low-rainfall rainfed wheat production zone (at one site: Khemis Zemamra). The trials of these lines were conducted with four replications. Plot sizes used for the trials were $10 \mathrm{~m}$ long by $1.8 \mathrm{~m}$ wide with a $20-\mathrm{cm}$ row spacing for rainfed 
sites and $8 \mathrm{~m}$ long by $1.8 \mathrm{~m}$ wide with a $20-\mathrm{cm}$ row spacing for the irrigated site.

DNA marker assays using polymerase chain reaction were used to determine genotypes for the Rht loci, which control height (Ellis et al., 2002), and the 1BL:1RS translocation (STS marker iag95; Mago et al., 2002), which controls leaf rust resistance gene Lr26 (Mago et al., 2005). The analysis revealed that semidwarf characteristics of 00DHBW103, 00DHBW146, and 00DHBW300 were due to the Rht-B1b genotype (Fig. 1A). The absence of the 1RS translocation (Fig. 1B) in 00DHBW103, 00DHBW146, and 00DHBW300 indicates that the leaf rust resistance in 00DHBW103, 00DHBW146, and 00DHBW300 was not due to the resistance gene $L r 26$ present in the parent Tilila.

Analysis of variance (Steel and Torrie, 1980) and Duncan's test (Duncan, 1955) were performed using the MSTATC statistical program (Ver. 3, Michigan State Univ., East Lansing). Duncan's multiple range test was used for comparing means in the trials conducted by INRA, whereas in the ONSSA nationwide varietal trials, the Dunnett test (Dunnett, 1955) was used to compare mean of the every experimental line with the mean of the same local check.

\section{Seed Purification and Increase}

In 2005-2006, 200 spikes of 00DHBW300 were planted one spike per row in 1-m rows. The resulting seeds were planted in small plots in 2006-2007 for seed increase. Since 00DHBW300 was a doubled haploid, the line was homogenous and no variants or off-types were observed.

\section{End-Use Quality Analyses}

End-use quality evaluations of 00DHBW300 and two checks (Achtar and Kenz) were conducted by ONSSA, Morocco, on a sample composited from grain of the nationwide trial in 2009-2010. The sample was evaluated for grain volume weight $\left(\mathrm{kg} \mathrm{hL}^{-1}\right), 1000$-grain weight $(\mathrm{g})$, protein content (\%), Hagberg vales (s), sedimentation index (Zeleney test in $\mathrm{mL}$ ), and Alveograph W, G, and P/L (FranceAgriMer, 2010).

\section{Characteristics}

In the nationwide trials in 2008-2009 and 2009-2010, the yield of 00DHBW300 was either significantly higher than or

\section{A) Marker assay for Rht-B1b dwarfing gene} Doubled haploid lines

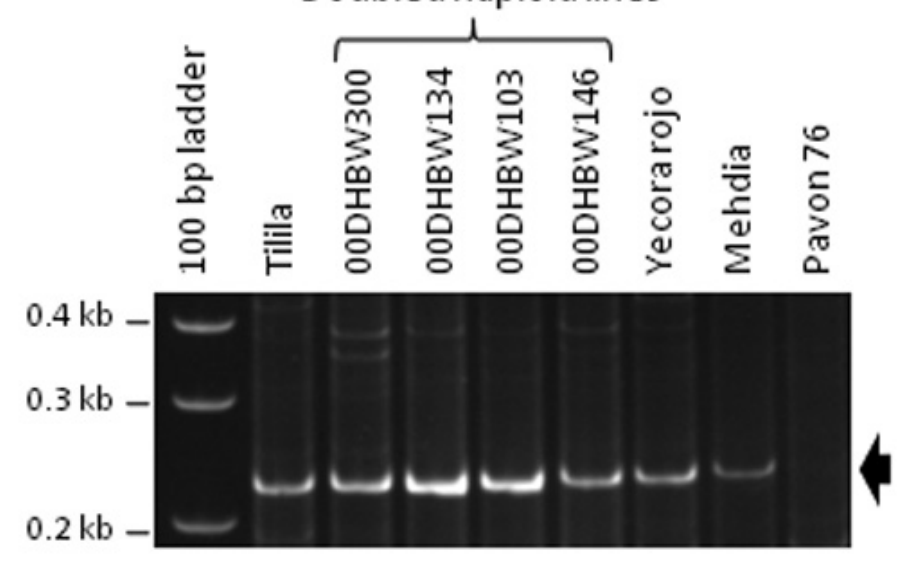

B) Marker assay for 1BL.1RS translocation

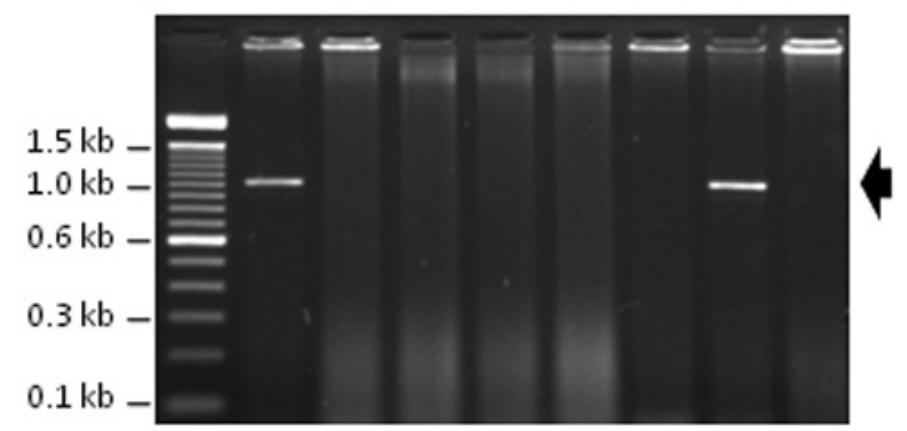

Figure 1. DNA marker assays for Rht-B1b and 1BL.1RS in the selected wheat cultivars and doubled haploid lines. (A) For Rht-B1b (dwarfing gene) assays, the BF and MR1 primer set was used for PCR (Ellis et al., 2002). PCR products were separated on $8 \%$ native polyacrylamide gels. The arrow indicates the diagnostic band. (B) For 1BL.1RS assays, STS marker iag 95 was used (Mago et al., 2002) and PCR products were separated on $1.2 \%$ agarose gels. The arrow indicates the diagnostic band.

on par with the means of the two checks, Achtar and Kenz (Table 1), except in Mrisa, where the yield was significantly

Table 1. Comparison of grain yield of Kharoba and the cultivars tested on three wheat production zones of Morocco during the nationwide trials 2008-2009 and 2009-2010.

\begin{tabular}{|c|c|c|c|c|c|c|c|c|c|c|}
\hline \multirow[b]{3}{*}{ Cultivar ${ }^{\dagger}$} & \multirow{2}{*}{\multicolumn{2}{|c|}{$\begin{array}{l}\text { Irrigated zone } \\
\text { Ouled Gnaou }\end{array}$}} & \multicolumn{6}{|c|}{ High-rainfall rainfed zone } & \multirow{2}{*}{\multicolumn{2}{|c|}{$\frac{\text { Low-rainfall rainfed zone }}{\text { Khamis Zemamra }}$}} \\
\hline & & & \multicolumn{2}{|c|}{ Bouznika } & \multicolumn{2}{|c|}{ Marchouch } & \multicolumn{2}{|c|}{ Mrisa } & & \\
\hline & 2008-9 & 2009-10 & 2008-9 & 2009-10 & 2008-9 & 2009-10 & 2008-9 & 2009-10 & 2008-9 & 2009-10 \\
\hline & & & & & - k & $\mathrm{gha} \mathrm{a}^{-1}$ & & & & 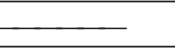 \\
\hline $\begin{array}{l}\text { Kharoba } \\
\text { (00DHBW300) }\end{array}$ & 5828 & 2631 & 2211 & 1286 & 5691 & 5190 & 5132 & 2995 & 4039 & 3510 \\
\hline Achtar (Check) & 4387 & 5123 & 1922 & 2281 & 4449 & 4400 & 6207 & 1791 & 4031 & 2292 \\
\hline Kenz (Check) & 4939 & 3007 & 1699 & 1957 & 3473 & 2652 & 6662 & 1587 & 2984 & 1507 \\
\hline Mean of checks & 4663 & 4065 & 1811 & 2129 & 3961 & 3526 & 6434 & 1689 & 3508 & 1900 \\
\hline Average all entries ${ }^{\ddagger}$ & 5692 & 4169 & 2810 & 2071 & 5304 & 4949 & 6152 & 2479 & 3884 & 2695 \\
\hline Dunnett test $(p<0.05)$ & 1605 & 1993 & 1650 & 1080 & 1774 & 1530 & 1202 & 1407 & 1605 & 1168 \\
\hline
\end{tabular}

The trials include many experimental lines not shown in the table.

${ }^{\ddagger}$ Average of all the values for the trait for the entries that were in the trial; includes values for many experimental lines not shown in the table. 
( $p \leq 0.05)$ reduced during 2008-2009. The zone-wise analysis of the yield performance of 00DHBW300 across cropping year showed no significant difference with or was on par with mean of the two checks (data not shown).

The composite grain sample from the 2009-2010 nationwide trial was analyzed for end-use quality traits. Table 2 shows that among the comparison cultivars, 00DHBW300 was better than the average of two checks for each end-use quality characteristic, namely grain volume weight, 1000grain weight, protein content, Hagberg values, and sedimentation index. The Alveograph values $\mathrm{W}, \mathrm{G}$, and $\mathrm{P} / \mathrm{L}$ for 00DHBW300 were $257.5,18.5$, and 1.65 , respectively, which is 100,79 , and $177 \%$, relative to the mean of the two checks (Achtar and Kenz). Based on these observations on yield and end-use quality, 00DHBW300 was approved for release in December 2010 by ONSSA, Morocco. 00DHBW300 was given the name Kharoba.

Kharoba is a vernacular term that is used by farmers in the Doukkala and Chaouia regions of Morocco to express a unit of volume used to quantify the wheat harvest. Since the cultivar 00DHBW300 has a higher grain volume weight compared with other cultivars, farmers would expect to get greater returns (per Kharoba-volume) when selling it in the market, where grain is quantified in terms of weight. Hence, the name Kharoba was chosen for 00DHBW300.

Kharoba is a short, semidwarf (Rht1), erect hard red spring wheat cultivar. At the boot stage, the plants are green and have twisted, inclined, nonwaxy flag leaves. The spike is fusiform, erect, and awned. Most of the awns are distributed along the top three-fourths of the spike. The glumes have slightly bent beaks and low internal hairs. The outer surface of the terminal section of rachis is covered with little hairs. The seed shape is oval, with a midsized brush of short-to-medium hairs. The straw of Kharoba is thick but has little pith.

Table 2. Average of several end-use quality traits of Kharoba and the checks across the three wheat production zones of Morocco (the 2009-2010 nationwide trial).

\begin{tabular}{lcccc}
\hline & $\begin{array}{c}\text { Grain } \\
\text { volume } \\
\text { weight }\end{array}$ & $\begin{array}{c}\text { 1000-grain } \\
\text { weight }\end{array}$ & $\begin{array}{c}\text { Hagberg } \\
\text { values }\end{array}$ & $\begin{array}{c}\text { Sedimentation } \\
\text { index } \\
\text { (Zeleny test) }\end{array}$ \\
\hline Kultivar & $\mathrm{kg} \mathrm{hL}^{-1}$ & 9 & $\mathrm{~s}$ & $\mathrm{~mL}$ \\
Kharoba (00DHBW300) & 82.1 & 29.16 & 464 & 35.33 \\
Achtar (check) & 75.13 & 25.53 & 409.7 & 29.66 \\
Kenz (check) & 76.41 & 29.83 & 451.7 & 39.66 \\
\hline
\end{tabular}

Table 3. Agronomic characteristics of Kharoba and four other cultivars tested in the advance yield trials 2005-2006 at Sidi EI Aidi station.

\begin{tabular}{lccc}
\hline Cultivar & $\begin{array}{c}\text { Plant } \\
\text { height }\end{array}$ & $\begin{array}{c}\text { Days to } \\
\text { heading }\end{array}$ & $\begin{array}{c}\text { Days to } \\
\text { maturity }\end{array}$ \\
\hline Kharoba (00DHBW300) & $\mathrm{cm}$ & & \\
Massira & 85 & 95 & 120 \\
Achtar & 85 & 89 & 110 \\
Kenz & 90 & 98 & 115 \\
Aguilal & 90 & 87 & 110 \\
\hline
\end{tabular}

Table 3 shows the data from the 2005-2006 advanced yield trial at Sidi El Aidi for plant height at maturity, days to heading, days to maturity, and grain yield. The plant height of Kharoba averaged $85 \mathrm{~cm}$, which was equal to or shorter than those of Massira $(85 \mathrm{~cm})$, Achtar $(90 \mathrm{~cm}), \mathrm{Kenz}$ $(90 \mathrm{~cm})$, and Aguilal $(95 \mathrm{~cm})$ (Table 3). In nationwide trials (2008-2009 and 2009-2010), Kharoba was rated as a short cultivar compared with all the other check cultivars (data not shown). The mean of days from planting to heading of Kharoba was 95 d, 3 d earlier than Achtar, and 6, 8, and $10 \mathrm{~d}$ later than those of Massira, Kenz, and Aguilal, respectively. Kharoba had $120 \mathrm{~d}$ of growth on average, which makes it relatively late maturing compared with the other cultivars (Table 3).

\section{Disease and Pest Resistance}

The reaction of Kharoba to disease and insect pests (0-9, where 0 = immunity to 9 = very susceptible, Hall et al., 2011) has been evaluated across diverse Moroccan environments. Leaf rust is endemic in the major wheat-growing zones of Morocco (Singh et al., 2002). Based on field valuation for resistance to leaf rust in the advanced yield trials of 2003-2004 and 2004-2005 in four environments (Sidi el Aidi, Jamaa Shaim, Tassaout, and Zemamra), Kharoba was resistant (0-1) to leaf rust throughout the plant growth. Field evaluation of Kharoba during the 2009-2010 cropping season (which experienced severe yellow rust incidence in Morocco, ICARDA, 2011) revealed resistance (0-1) to yellow rust under the natural inoculations. When planted in an FHB evaluation field at Sidi El Aidi experimental station during the 2010-2011 cropping season, Kharoba showed resistance (0-1), whereas all the other tested Moroccan cultivars were susceptible to the disease. Both greenhouse and field evaluations clearly showed that Kharoba is resistant (0-1) to the Hessian fly.

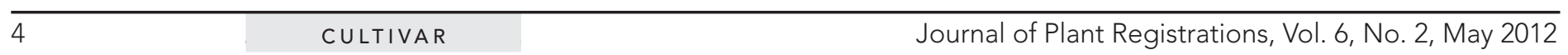

\section{Availability}

Kharoba has been registered under the Moroccan Plant Variety Protection Act and seed has been deposited with INRA-Morocco. Seed of Kharoba has also been deposited in the National Plant Germplasm System, where it will become available for distribution $20 \mathrm{yr}$ after the date of publication. Before termination of the Moroccan plant breeder's rights and distribution by NPGS, all seed requests should be sent to the corresponding author. If this cultivar is used as a parent in the development of new cultivars, it is requested that recognition be made of its use.

\section{Conclusions}

Kharoba is a moderately short, hard red spring bread cultivar suitable for cultivation in irrigated and rainfed zones of Morocco. Kharoba has resistance to leaf rust, yellow rust, Hessian fly, and Fusarium head blight. Kharoba is the only registered cultivar in Morocco with resistance to FHB. Khoroba is the first cultivar of bread wheat developed using doubled haploid technology in Morocco (INRA, 2011). 


\section{Acknowledgments}

SMU is grateful to the ICARDA/Morocco Collaborative Grants Program for the support. We thank Ms. Fatima Henkrar for the technical help.

\section{References}

Abbad-Andaloussi, F., and A. Chahbar. 2005. La création variétale à l'INRA, méthodologie, acquis et perspectives. Institut National de la Recherche Agronomique, Rabat, Morocco.

Duncan, D.B. 1955. Multiple range and multiple F tests. Biometrics 11:1-42. doi:10.2307/3001478

Dunnett, C.W. 1955. A multiple comparisons procedure for comparing several treatments with a control. J. Am. Stat. Assoc. 50:10961121. doi: $10.2307 / 2281208$

Ellis, M.H., W. Spielmeyer, K.R. Gale, G.J. Rebetzke, and R.A. Richards. 2002. "Perfect" markers for the Rht-B1b and Rht-D1b dwarfing genes in wheat. Theor. Appl. Genet. 105:1038-1042. doi:10.1007/ s00122-002-1048-4

FranceAgriMer. 2010. Quality of French soft wheats, 2010 harvest. FranceAgriMer, Montreuil-sous-Bois, France. Available at http:// www.onigc.fr/pdf/FR/qbt0910A.pdf (verified 13 Feb. 2012).

Hall, M.D., C.A. Griffey, A. Green, S. Liu, P. Gundrum, G. Berger,et al. 2011. Registration of 'Vision 30' wheat. J. Plant Reg. 5:353-359. doi:10.3198/jpr2011.03.0183crc

ICARDA. 2011. Research action: Strategies to reduce the emerging wheat stripe rust disease. ICARDA, Aleppo, Syria. Available at http://icardablog.files.wordpress.com/2011/06/icarda-stripe-rustresearch-to-action-report_low-res1.pdf (verified 23 Jul. 2011).

Institut National de la Recherche Agronomique (INRA). 2011. Kharoba, first bread wheat variety from the doubled haploid method. In INRA 2010 activity report, Institut National de la Recherche Agronomique, Rabat, Morocco.
Karrou, M. 2003. Conduite du blé au Maroc. Institut National de la Recherche Agronomique, Rabat, Morocco.

Mago, R., H. Miah, G.J. Lawrence, C.R. Wellings, W. Spielmeyer, H.S. Bariana, et al. 2005. High-resolution mapping and mutation analysis separate the rust resistance genes $\operatorname{Sr} 31, \operatorname{Lr} 26$ and $\operatorname{Yr} 9$ on the short arm of rye chromosome 1. Theor. Appl. Genet. 112:41-50. doi:10.1007/s00122-005-0098-9

Mago, R., W. Spielmeyer, G.J. Lawrence, E.S. Lagudah, J.G. Ellis, and A. Pryor. 2002. Identification and mapping of molecular markers linked to rust resistance genes located on chromosome 1RS of rye using wheat-rye translocation lines. Theor. Appl. Genet. 104:13171324. doi:10.1007/s00122-002-0879-3

Miller, C.O. 1963. Kinetin and kinetin-like compounds. p. 194-202. In H.F. Linsken and M.V. Tracey (ed.) Modern methods of plant analysis. Vol. 6. Springer-Verlag, Berlin, Germany.

Mujeeb-Kazi, A., V. Rosas, and S. Roldan. 1996. Conservation of the genetic variation of Triticum tauschii (Coss.) Schmalh. (Aegilops squarrosa auct. non L.) in synthetic hexaploid wheats (T. turgidum L.s.lat $\times$ T. tauschii; $2 n=6 x=42$, AABBDD) and its potential utilization for wheat improvement. Genet. Resour. Crop Evol. 43:129134. doi:10.1007/BF00126756

Prescott, J.M., P.A. Burnett, E.E. Saari, J. Ranson, J. Bowman, W. de Milliano, R.P. Singh, and G. Bekele. 1986. Wheat diseases and pests: A guide for field identification. CIMMYT, Mexico.

Singh, R.P., J. Huerta-Espino, and A.P. Roelfs. 2002. The wheat rusts. p. 567. In B.C. Curtis et al. (ed.) Bread wheat: Improvement and production. FAO Plant Production and Protection Ser. No. 30. FAO, Rome. Available at http://www.fao.org/DOCREP/006/Y4011E/ Y4011E00.HTM (verified 24 Jul. 2011).

Steel, R.G.D., and J.H. Torrie. 1980. Principles and procedures of statistics: A biometrical approach. McGraw-Hill, New York.

Wang, P., and Y.R. Chen. 1986. A study on the application of C17 medium for anther culture. Acta Bot. Sin. 28:41-45. 